\title{
Regeneration of Class II Furcation Defects: Determinants of Increased Success
}

\author{
Arthur Belém NOVAES Jr. \\ Daniela Bazan PALIOTO \\ Patrícia Freitas de ANDRADE \\ Julie Teresa MARCHESAN
}

Department of Bucco-Maxillo-Facial Surgery and Traumatology and Periodontology, Faculty of Dentistry of Ribeirão Preto, University of São Paulo, Ribeirão Preto, SP, Brazil

\begin{abstract}
One of the most important indications for guided tissue regeneration (GTR) treatment is class II furcation lesion. However, periodontal regeneration of this type of defect, although possible, is not considered totally predictable, especially in terms of complete bone fill. Many factors may account for variability in the response to regenerative therapy in class II furcation. The purpose of this review is to assess the prognostic significance of factors related to the patient (smoking, stress, diabetes mellitus, acquired immunodeficiency syndrome and other acute and debilitating diseases, and the presence of multiple deep periodontal pockets), local factors (furcal anatomy, defect morphology, thickness of gingival tissue and tooth mobility), surgical treatment (infection control, bone replacement grafts combined with barriers or GTR alone, type of barrier and surgical technique), and postoperative period (plaque control, membrane exposure, membrane retrieval and a regular supportive periodontal care program) for successful of GTR in class II furcations.
\end{abstract}

Key Words: guided tissue regeneration, class II furcation lesion, risk factors.

\section{INTRODUCTION}

The ultimate objective of periodontal therapy is to regenerate tissues lost as a consequence of periodontal disease. Histological and clinical studies have reported the potential of guided tissue regeneration (GTR) to regenerate alveolar bone, cementum and the periodontal ligament (1-10). In GTR, a barrier is inserted between the root surface and the gingival tissues to inhibit the apical migration of the epithelium and gingival connective tissue of the flap, allowing the granulation tissue derived from the periodontal ligament and osseous tissues to repopulate the space adjacent to the denuded root surface. These cells have the ability to differentiate into osteoblast-like cells and cementoblast-like cells, as well as new periodontal ligament fibroblasts and thereby promote tissue regeneration (11). One of the most important indications for GTR is class II furcation lesion in mandibular molars and interproximal defects. Clinical observations of GTR have shown more favor- able outcomes in mandibular class II furcations and facial class II maxillary defects compared to limited success in other class II or class III defects (12). However, Novaes and Novaes (13) reported 8 different situations of class II furcations in which GTR is not indicated: a) lack of access for adequate debridement of the furcation, b) endodontic or prosthetic perforations in the furcation areas of the roots, c) crown lengthening procedures that invade the furcations, d) root proximities untreatable by the restorative alveolar interface (RAI) technique, e) extensive gingival recessions, f) deep caries involving the roots, g) untreatable endo-perio lesions, and h) longitudinal root fractures. In these cases, hemisection is recommended.

Clinical studies have shown that GTR can improve the response of class II furcation defects to therapy by means of pocket reduction, gain in clinical attachment levels and bone defect fill. The improvement in these clinical parameters plus the potential of creating new attachment leads to the consideration of GTR as the 
treatment of choice in this type of periodontal defect. GTR has offered better results than open-flap debridement or bone replacement grafts alone in mandibular class II furcation (14).

The regeneration of class II furcation lesion, although possible, is not considered a totally predictable procedure, especially in terms of complete bone fill (15). Despite achieving significant positive gains in new attachment using GTR, consistently successful treatment of furcation defects with membrane techniques remains a challenge. Furcation morphology may restrict access for adequate debridement and root instrumentation and may have a reduced source of available cells and blood supply from the periodontal ligament and bone defect. One important factor for successful regeneration at furcation and non-furcation sites is the amount of periodontium that remains apical and lateral to the defect. Coronal migration of cells originating from the periodontal ligament and bone marrow spaces is particularly critical to the healing outcome following periodontal regenerative procedures in furcation defects.

These and other factors may account for variability in the response to regenerative therapy in class II furcation. To increase the predictability and clinical success of regenerative therapy, factors related to the patient, furcation, surgical treatment, and postoperative period should be considered.

\section{PATIENT FACTORS INFLUENCING SUCCESSFUL REGENERATION}

Each patient has a different healing potential that can directly influence the response to treatment. The patient-related factors that have a negative influence on the regeneration of these lesions include smoking, stress, diabetes mellitus, acquired immunodeficiency syndrome and other acute and debilitating diseases, and the presence of multiple deep periodontal pockets. Age, gender and type of periodontal disease do not seem to play a major role in regenerative therapy $(10,16)$.

Smoking. Epidemiological and longitudinal studies have shown an increased prevalence of periodontal disease and progression rate among smokers compared to non-smokers (17). Evidence has indicated that smokers present a less favorable response following both non-surgical and surgical periodontal therapy (18).

Various factors contribute to the deleterious periodontal effects of smoking, including alterations of the microflora and host response (17). The proposed mechanisms of the negative periodontal effects of smoking are decreased vascular flow, altered neutrophil function, decreased IgG production and lymphocyte proliferation, increased prevalence of periopathogens, altered fibroblast attachment and function, difficulty in eliminating pathogens by mechanical therapy, and negative local effects on cytokine and growth factor production (17). These deleterious effects have been related to the presence of more than 4000 toxic constituents in cigarette smoke (19).

Cigarette smoking has been associated with a reduced healing response following GTR treatment $(14,19,20)$. Evidence indicates that the impact of smoking on regenerative therapy is more significant in the tissue maturation phase $(19,20)$. Machtei et al. (20) recommended that when GTR is performed for class II furcation defects in smokers, anti-infective therapy should be incorporated into the treatment protocol to enhance the regenerative outcome. In that study, the experimental (anti-infective therapy) and control groups gained similar levels of tissue at membrane retrieval; however, the experimental group exhibited significantly less tissue loss between retrieval and 1-year reentry, indicating that the effect of smoking is crucial at the tissue maturation phase. Thus, while smoking prevented tissue maturation and mineralization, the antiinfective protocol enhanced these processes, resulting in a more favorable outcome. Adjunctive systemic or local antimicrobial therapy has been recommended in smokers due to evidence suggesting that subgingival pathogens are more difficult to eliminate in smokers following scaling and root planing (17).

Ah et al. (18) reported that smokers of more than 10 cigarettes a day respond less favorably to both conservative and surgical periodontal therapy than do non-smokers. Kaldahl et al. (21) noted that heavy smokers ( $>20$ cigarettes per day) respond less favorably than light smokers $(<20$ cigarettes per day). It is important to note that former smokers respond to nonsurgical and surgical therapy in a similar manner to those who have never smoked (17). Thus, tobacco cessation may result in better predictability and an improved regenerative response; however, the period that is required for host responses to return to normality following cessation is yet to be determined.

Stress. The influence of stress on periodontal regenerative therapy has not yet been studied. However, 
recently, psychological stress has been considered to be a possible risk factor for periodontal breakdown. The proposed mechanisms for the negative periodontal effects of stress include neglect of oral hygiene, changes in diet, increase in smoking and other pathogenic oral behaviors, bruxism, alterations in gingival circulation, changes in saliva, endocrine imbalances and lowered host resistance (22).

Diabetes mellitus. The diabetic's susceptibility to periodontal disease and impaired wound healing can affect the progression of diabetes mellitus and the response to periodontal therapies such as GTR (23). Various features or events seem to be responsible for delayed wound healing in diabetic patients, such as impaired cell function, decreased tissue oxygenation, microvascular complications, increased collagenase production, deficiency in growth factors activity, deregulation of cytokines at the wound site, and decreased migration of periodontal ligament cells, which can interfere in the regenerative process $(23,24)$.

A negative prognosis might be anticipated in patients with insulin-dependent diabetes mellitus, especially if their glucose levels vary (14). Treating furcation defects with GTR can be an option in well-controlled diabetics; however, the possibility of postsurgical complications should be considered. If complications arise because of delayed wound healing, treatment results may be less successful than expected. Thus, patients with diabetes require close supervision and frequent monitoring of the regenerated site to achieve long-term success.

Other systemic conditions. A negative prognosis might be anticipated in HIV-positive patients with other clinical or immunological deficiencies, in patients with rheumatoid arthritis, and other immune-complex diseases. High doses of irradiation in patients with a history of head and neck tumors might be detrimental to the regenerative process (14).

Presence of multiple deep periodontal pockets. GTR should be performed in patients with low levels of pathogens in the oral cavity. Barrier membranes are at risk of becoming contaminated within 3 min of intraoral membrane manipulation in individuals with multiple deep periodontal pockets, bleeding on probing in other parts of the dentition, and high subgingival levels of putative periodontopathogens. Research has shown a negative correlation between bacterial contamination of the membrane and clinical attachment gain (25).

\section{LOCAL FACTORS INFLUENCING SUCCESSFUL REGENERATION}

The predictability of GTR in class II furcations is also strongly influenced by local factors, such as furcal anatomy, defect morphology, thickness of gingival tissue, and tooth mobility $(8,10,26-29)$.

\section{Furcal Anatomy}

The furcal anatomy-related factors are the presence of cervical enamel projection, enamel pearls, root or root trunk concavities, bifurcation ridge, accessory canals, furcation entrance dimension and length of root trunk.

Cervical enamel projections and enamel pearls. Cervical enamel projections and enamel pearls may contribute to plaque accumulation and furcal invasion, hence, should be removed by odontoplasty during regenerative procedures. New attachment cannot be observed over these anatomical conditions (27).

Root concavity. Areas of root concavity also contribute to plaque accumulation and are covered by more cementum than are the adjacent convexities. This may have clinical significance because of the ability of the cementum to hold toxic bacterial products (27). Root surfaces exposed to the environment of a periodontal pocket may become hypermineralized. In addition to a direct cytotoxic effect on host cells, these surfaces may represent a poor substrate for plasma protein adsorption and subsequent fibrin adhesion (30). Thus, ultrasonic, hand and rotary instruments must be used for more effective decontamination in furcation areas, as well as the chemical conditioning of the scaled roots.

Root trunk concavities. The presence of root trunk concavities in molars, especially mandibular molars, has been reported to have possible effects on the regenerative results. Pustiglione et al. (31) and Kon et al. (32) reported that $100 \%$ of mandibular molars have root trunk concavities with a mean depth of $1.12 \mathrm{~mm}$ in first molars and $1.05 \mathrm{~mm}$ in mandibular second molars. Dunlap and Gher (33) determined the location of the first detectable buccal and lingual root concavities at 0.7 $\mathrm{mm}$ and $0.3 \mathrm{~mm}$ apical to the cemento-enamel junction, respectively, which progressively deepened to reach the furcation. The concavities of the root trunks negatively influence the results of GTR because adequate adapta- 
tion of the membranes, when placed 2 to $3 \mathrm{~mm}$ apical to the cemento-enamel junction, does not occur. This permits apical migration of the junctional epithelium, thus impeding the regeneration process. This was demonstrated by Novaes et al. (8), who evaluated the effect of the concavities on the regeneration of class II furcation lesions histomorphometrically in dogs. The authors suggested that a modification in the design of the membrane collars would allow more intimate adaptation of the membranes to the surface of the root trunk concavities, favoring the regeneration of periodontal tissues. In lesions treated with the modified membrane there was significant regeneration with less junctional epithelium migration and more bone regeneration. Villaça et al. (9) confirmed these results in humans and reported greater horizontal resolution of class II furcation defects treated with the modified membrane. Thus, these studies concluded that the collars of the membranes should be modified to improve regenerative results when root trunk concavities are present $(8,9)$.

Bifurcation ridge. The bifurcation ridge is an anatomic structure formed mostly of cementum that originates from the mesial surface of the distal root, runs across the bifurcation and ends high up on the mesial root. This creates niches for plaque accumulation and has been found in $70-73 \%$ of mandibular molars. Odontoplasty should be considered in the presence of severe bifurcation ridges to ensure proper root surface preparation (27).

Accessory canal. Histologic studies have demonstrated accessory canals in the region of furcation (27). Endodontic infections can cause periodontal disease in the furcation region of molars by accessory canals and impair the healing response following GTR.

Entrance of the furcation. The architecture of the furcation entrance is an important factor for root preparation access, representing a major determinant of treatment success. Bower (34) has shown that the diameter of the furcation entrance in molars is smaller than the blade width of commonly used curettes in 58\% of the furcations examined, hindering effective instrumentation of these areas. Matia et al. (35) showed that calculus removal in narrow furcations (less than 2.3 $\mathrm{mm}$ ) is significantly better with open ultrasonic debridement than with open hand debridement; however, in wide furcations, there is no significant difference between the two approaches of calculus removal. Hence, it appears that hand instrumentation alone may not be adequate for complete root surface preparation in all furcation areas.

Length of root trunks. Molars with short root trunks are generally considered to be at higher risk for developing furcation involvement than teeth with long root trunks and are also the best candidates for tooth resection procedures (27). Bowers et al. (10) demonstrated that molars with the longest root trunks (5-6 $\mathrm{mm}$ ) tended to respond more often with complete furcation closure following GTR therapy than teeth with shorter root trunks (100\% versus $71 \%$, respectively), although this difference failed to reach statistical significance. Hutchens (36) suggested that short root trunk length is considered to be less favorable for membrane coverage, coronal positioning and flap adaptation against the tooth. In contrast, Horwitz et al. (26) reported that long root trunk has a negative influence on the success of regenerative therapy. The results of this study indicated that long root trunks were associated with less favorable clinical horizontal probing attachment gains.

Type of tooth. Mandibular first and second molars frequently exhibit differences in root morphology and furcation access, which may affect surgical management (10). Mandibular first molars have shorter root trunks, which may account for the higher prevalence of furcation defects in mandibular first molars compared to second molars. Mandibular first molars frequently exhibit complex cementum morphology, an intermediate bifurcation ridge and intraradicular root concavities. Mandibular second molars have the longest root trunks and smaller root divergence, which may impair access for root preparation. Bowers et al. (10) demonstrated that despite comparable percentages of first and second molars with incomplete furcation closure, second molars exhibited a trend towards a higher proportion of defects with residual class II furcation. However, Machtei et al. (16) showed that first and second molars responded similarly to regenerative treatment.

The GTR procedure has a limited application for class II furcations of maxillary molars. Pontoriero and Lindhe (12) observed the largest clinical improvement in class II furcations of mandibular molars, followed by buccal class II furcations of maxillary molars and with interproximal furcation lesions exhibiting the least or no improvement. The authors reported that the reason for the different outcome of GTR in maxillary and mandibular furcation defects is most likely related to the anatomy of the defects, the presence of deep grooves in the root 
surface of the maxillary furcation, the limited access for root surface debridement, and the amount of remaining periodontium facing the defect. Furthermore, in interproximal furcation lesions, adaptation of the membranes is more difficult.

\section{Defect Morphology}

The clinical success of furcation therapy also appears to be strongly related to defect morphology. In a prospective study performed by Bowers et al. (10), multiple factors predictive of clinical outcome in the treatment of facial class II furcations in mandibular molars were identified: a) probing pocket depth, b) horizontal probing attachment level, c) distance of furcation roof to base of defect, d) distance of furcation roof to crest of bone, e) interproximal bone height, f) distance of bone crest to base of defect, g) root divergence, h) horizontal depth of defect, and i) furcation defect volume.

Probing pocket depth. Increases in presurgical pocket depth were associated with a significant reduction in complete furcation closure. However, Horwitz et al. (26) reported that a deep probing depth at the furcation site at baseline increases the likelihood for more favorable horizontal attachment gain in furcations. Machtei et al. (16) also demonstrated that the greater the initial pocket depth, the greater the potential for periodontal regeneration, suggesting that initial probing depth might be a useful indicator for the regenerative potential of a given site.

Horizontal probing attachment level. Increased baseline horizontal probing attachment level was associated with decreased clinical closure. Furcations with horizontal probing depths of $5 \mathrm{~mm}$ or greater demonstrated a lower likelihood of complete closure.

Distance of bone crest to base of defect. This measurement failed to account for differences in outcome relative to furcation closure. However, Cortellini et al. (37) reported that the depth of the infraosseous component of the defect is one of the most important factors in achieving the maximum regenerative potential. Anderegg et al. (38) also reported that the deeper the vertical component, the greater the repair.

Distance of furcation roof to base of defect. Increases in this measurement were associated with decreased clinical closure. Complete furcation closure was observed in $63 \%$ of defects with a distance of furcation roof to base of defect of $4 \mathrm{~mm}$ or greater. Machtei and Schallhorn (14) reported that if this measurement is lower than $4 \mathrm{~mm}$ and associated with defects that are mainly intra-osseous there is a better prognosis than the same measurement associated with defects that are mainly supra-osseous.

Distance of furcation roof to crest of bone. Increases in the distance of furcation roof to crest of bone were associated with a lower probability of complete furcation closure. Over $90 \%$ of defects with this measurement of $2 \mathrm{~mm}$ or less demonstrated complete furcation closure, compared to $67 \%$ of sites with a measurement of $3 \mathrm{~mm}$ or more.

Interproximal bone height. Teeth with interproximal bone height at the same level or superior to the roof of the furcation resolved with complete closure in a significantly higher percentage of cases (94\% complete closure) than sites where interproximal bone was below the roof of the furcation (70\% complete closure). Horwitz et al. (26) reported that, if there is bone coronal to the furcation fornix at the mesial and distal aspect of the tooth, coverage and stabilization of the membrane may be achieved with a coronally positioned flap. Under these conditions, the area of periodontal ligament available to provide cells to colonize the blood clot within the defect is larger than in the situation where the fornix is located coronal to the alveolar crest.

Root divergence. Increases in root divergence measured at crest of bone were associated with decreases in complete furcation closure. Complete furcation closure was achieved in $61 \%$ of defects with associated root divergence of $4 \mathrm{~mm}$ or greater, compared to $93 \%$ of defects with root divergence of $3 \mathrm{~mm}$ or less. However, it should be noted that furcation defects must have a root divergence sufficient to allow root preparation with hand, rotary, and ultrasonic instrumentation. Horwitz et al. (26) also demonstrated that a wide furcation entrance has a negative influence on the success of GTR therapy.

Horizontal defect depth. Furcation defects with a horizontal depth of $5 \mathrm{~mm}$ or greater measured at the level of the crest of bone demonstrated a lower probability of complete closure (10). Complete furcation closure was obtained in 52\% of cases, whereas defects with a horizontal depth of $4 \mathrm{~mm}$ or less responded with complete furcation closure in $84 \%$ of cases. Thus, in general, the findings of this study suggest that the less severe the defect, the greater the likelihood of achieving 
complete clinical furcation closure.

\section{Thickness of Gingival Tissue}

The amount and quality of the gingival tissue that will cover the membrane is also important. Inadequate gingival width and thin keratinized tissue should be analyzed because it can lead to gingival recession. Anderegg et al. (29) demonstrated that there is less posttreatment recession for tissue thickness greater than 1 $\mathrm{mm}$ than tissue thickness less than or equal to $1 \mathrm{~mm}$. Thus, these authors suggest that the thickness of gingival tissue covering the membrane appears to be a factor to consider if post-treatment recession is to be minimized or avoided.

Many factors can account for this. The revascularization of any flap may be further compromised by blockage of the potential blood supply from the periodontal ligament and bone defect to the connective tissue flap by a membrane. The thicker the connective tissue, the better the potential circulatory pool and the greater the chance for flap survival. Mormann and Ciancio (39) demonstrated that flaps under tension become ischemic leading to necrosis. The blood supply in thin flaps is more likely to become compromised by tension than in thicker flaps of equal mobility. The likelihood of increased flap contraction associated with thin tissues might be magnified when placed over an ePTFE membrane, resulting in more postsurgery recession. Novaes et al. (40) reported that flaps with thin connective tissue are at greater risk for inflammationinduced postsurgery recession than thick flaps.

\section{Tooth Mobility}

Conflicting results exist concerning the effect that presurgical hypermobility has on surgical healing and, thus, on the post-therapeutic clinical outcome. Because of the scarcity of data available about the effect that tooth mobility has on periodontal regenerative therapy, the clinical relevance of mobility in regenerative therapy has not yet been elucidated. Trejo and Weltman (28) reported that intraosseous defects of teeth with Miller's class 1 and 2 mobility responded favorably to regenerative therapy. In contrast, Cortellini et al. (41) reported that the greater the tooth mobility is at baseline, the smaller the clinical attachment level gain would be 1 year after regenerative therapy.
In clinical practice, the question of whether to splint mobile teeth prior to regenerative therapy to improve the healing outcome often arises. Further studies are needed to validate or refute the regenerative potential of splinting. Machtei and Schallhorn (14) recommended that very mobile teeth be splinted prior to GTR in class II furcation defects. Trejo and Weltman (28) recommended the splinting of hypermobile teeth to improve patient comfort during post-therapeutic healing. However, the clinician must recognize progressing tooth mobility due to trauma, teeth under premature centric occlusal contact, and teeth under traumatic excursional interferences. Such occlusal discrepancies should be removed to minimize trauma and thus tooth mobility prior to regenerative therapy (28).

\section{SURGICAL FACTORS INFLUENCING SUCCESSFUL REGENERATION}

Surgical factors such as infection control, bone replacement grafts combined with barriers or GTR alone, type of barrier and surgical technique may also influence the regenerative results.

Infection control. Infection has been considered a major cause of incomplete healing with GTR. The ability of periodontal pathogens to produce cytotoxic products and gingival inflammation probably inhibits the coronal migration of periodontal fibroblasts on the tooth surface. Nowzari et al. (42) emphasized the importance of microbes on the tooth-facing surface of a barrier membrane. Sites free of pathogens on the membrane surface toward the tooth gained the most probing attachment, even in the presence of putative pathogens on the membrane surface facing the gingiva. This is probably due to their close proximity to the periodontal ligament cells. The findings of this study demonstrated the importance of controlling microbial pathogens in GTR. Patients on an 8-day course of amoxicillin/ clavulanate potassium therapy starting immediately prior to the membrane placement (500 mg $1 \mathrm{~h}$ prior to surgery and $500 \mathrm{mg}$ TID for 8 days thereafter) showed lower levels of periodontal pathogens in membranes and experienced significantly more gain of probing attachment than non-antibiotic treated patients.

Other anti-infective protocols have been suggested to prevent or control bacterial colonization in subgingival sites as well as in membranes, including systemic and topical antibiotic and antimicrobial admin- 
istration. Due to the limitations of systemically administered antibiotics, and especially the need for high drug concentration at the target site, the use of locally delivered antibiotics has been suggested (20). Although, there is no single accepted antimicrobial protocol used in conjunction with GTR therapy and no treatment has proven to be completely effective in preventing bacterial contamination of the membranes, we recommend the following protocol: amoxicillin/clavulanate potassium (875 mg, twice a day for 10 days, starting $24 \mathrm{~h}$ prior to surgery).

Surgical factors such as flap design and manipulation, placement of relaxing incisions, use of bone replacement grafts and membranes, suture materials and technique, and adequate root preparation appear to be the most important factors in determining whether or not the patient will have post-surgical infection. Thus, the timing of antimicrobial administration is of extreme importance. Although many clinicians prescribe systemic antibiotics at the end of the surgical procedure, a preferred timing would be to begin antibiotic therapy before surgery as cited earlier. The level of antibiotics that should be in the tissues at the time of surgery is determined by prescribing an adequate dosage so that bactericidal concentrations can be achieved at the time of surgery. This timing can also shorten the duration of antibiotic therapy. Potential benefits for regeneration include greatly reduced post-surgical infection, quicker healing, shorter post-surgical healing period, fewer side effects, and reduced discomfort and cost (43).

Other surgical anti-infective strategies include the use of chlorhexidine prior to surgery and postsurgery. The use of chlorhexidine prior to surgery can significantly reduce the intra-oral bacterial load, thus reducing the potential for infection (43).

Bone replacement grafts combined with barriers versus GTR alone. Despite the limited number of trials evaluating the outcome of furcation therapy in conjunction with GTR and different filling materials, there seems to exist a trend for better horizontal resolution of furcation using combined therapy $(2,3,7,38)$. The function of a grafting material in association with GTR would be as a scaffold to ensure clot stabilization and to provide and maintain space whenever the membrane may have the possibility to collapse, therefore, reducing the space for regeneration. Most studies used allogeneic or autogenous materials. Simonpietri-C et al. (7) demonstrated in a clinical study that the use of bovine- derived anorganic bone with GTR improved horizontal defect resolution in mandibular class II furcation defects. In 2003, Murphy and Gunsolley (44) performed a systematic review and concluded that the use of augmentation materials in addition to the physical barrier enhances the regenerative outcome of treatment of furcation defects with GTR.

The lack of agreement of studies on this issue may be attributed to differences in the selection criteria, the outcome variable used to determine success, diverse methodologies used to determine hard tissue measurements, difficulty to standardize the defects and other variables such as local and systemic factors. Another concern in evaluating the significance of findings is the relatively small sample often used in human clinical trials. It is very difficult to obtain a large sample of similar furcation defects, which increases the chances of a type II statistical error, i.e., failure to demonstrate any difference between different approaches when, in fact, it exists. Studies using large samples and additional long-term documentation with standardization of the study design, surgical technique and other variables are needed to assess the efficacy of adding bone grafting materials to the GTR procedure and to allow for more valid and meaningful comparisons between studies. However, considering the wide set of variables influencing the outcome in furcation defects and the difficulties in determining an outcome even during the surgical procedure, we recommend the use of filling material.

Type of barrier. A variety of biocompatible materials have been used as barriers in GTR. The nonabsorbable membranes made of expanded polytetrafluorethylene (e-PTFE) (Gore-Tex; W.L. Gore \& Assoc., Flagstaff, AZ, USA) are considered "gold standard" in regeneration, due to the number of studies examining this material (44). However, the literature indicates that from a clinical and histological standpoint, similar results can be achieved in GTR, whether bioabsorbable or non-bioabsorbable barriers are applied (5,6,44-46). Clinical studies comparing GTR therapy in class II furcation lesions with non-absorbable and bioabsorbable barriers demonstrated similar results for short- and long-term periods $(4,47)$.

The most prominent problems associated with the use of non-absorbable membranes are the need for a second surgical procedure for membrane removal that increases patient morbidity, and the high frequency of early membrane exposure that leads to bacterial con- 
tamination (48). Several studies showed that partial exposure of the e-PTFE membrane to the oral cavity occurred in $65-100 \%$ of the cases involving GTR (4951). These studies showed that the membranes may be heavily colonized by bacteria and that a negative relationship exists between clinical attachment gain and plaque colonization of the barrier material.

Bioabsorbable membranes do not require a second surgery because they are bioabsorbed without significant inflammatory reaction. The presence of a mild localized inflammatory reaction does not seem to compromise the clinical or histological results $(5,6)$. It can be assumed that a single-step surgical procedure would be more economical and comfortable. Furthermore, avoiding the second surgery means that the newly regenerated periodontal tissues will not be disturbed during the remodeling phase (30). Studies have reported that bioabsorbable membranes are at less risk for exposure than non-absorbable membranes (46). However, exposure may allow bacterial colonization resulting in early degradation and ultimately compromising the final outcome (52). Thus, based on this fact, we strongly suggest the use of the nonabsorbable membranes made of expanded polytetrafluorethylene (ePTFE).

Surgical technique. Periodontal regeneration is a technique-sensitive procedure requiring training and experience, even for a competent surgeon. Poor operative technique in membrane placement or surgical soft tissue management and failure to adequately cover the membrane can cause gingival recession and consequently membrane exposure. Pini Prato et al. (53) reported that the irritating effect of the membrane and the handling of the tissues may account for $1 \mathrm{~mm}$ recession observed at follow-up. In addition, flap margins can be inadvertently thinned during sulcular incisions and increase the risk of postsurgery recession. This effect might be magnified in thinner, more delicate tissues. Where esthetics is not an issue, some recession may be acceptable in posterior sites, especially if the furcation has been closed or if access for plaque control in the residual defect has been enhanced. Recession that creates root sensitivity, complicates plaque control, increases the risk for root caries, or results in an inadequate zone of keratinized attached tissue is not acceptable (29).

Other risk factors that have been implicated in GTR procedures include space maintenance under the barrier and membrane stability. Thus, special attention should be given to the tensile strength of the sutures of the flap in order to avoid any collapse of the membrane into the defect, and also to cover the entire membrane surface.

\section{POSTOPERATIVE FACTORS INFLUENCING SUCCESSFUL REGENERATION}

Postoperative factors such as plaque control, membrane exposure, membrane retrieval and a regular supportive periodontal care program may also influence the final results.

Plaque control. Optimal plaque control has been considered to be a crucial factor in regenerative outcome. It could be stated that plaque-infected teeth will lose attachment after any type of surgery. Numerous reports indicate that good oral hygiene, as reflected in low plaque scores, is associated with better regenerative responses $(14,16,28,43)$.

Membrane exposure. Membrane exposure does not necessarily mean infection and contamination that could consequently affect the regenerating tissue $(6,54)$. Novaes et al. (54) suggested that, even when large portions of the membranes are exposed, contamination by periodontopathic bacteria commonly associated with destructive periodontal disease can be controlled by preand postoperative use of antibiotics and topical chlorhexidine and thus good regenerative results can be achieved. In these cases, we currently recommend amoxicillin plus clavulanic acid ( $875 \mathrm{mg}$ ) every $12 \mathrm{~h}$ for 10 days, starting $24 \mathrm{~h}$ before the procedure. For patients showing membrane exposure after 10 days, an initial dose of $200 \mathrm{mg}$ doxycycline and then $100 \mathrm{mg}$ doxycycline once a day have been prescribed until membrane retrieval. However, other authors prescribe only topical chlorhexidine applications in order to limit bacterial colonization $(46,55)$. Newman (43) recommended removal of membranes associated with suppuration and/ or acute infection any time they are present. Bouchard et al. (46) prescribed antibiotic therapy when abscess developed. It is important to mention that acute postsurgical infections can lead to serious systemic complications. In these cases, the treatment should almost always include removal of the regenerative materials (43).

Membrane retrieval. Other risk factors that have been implicated in GTR procedures include time of 
membrane retrieval and soft tissue coverage of the newly formed tissue following membrane retrieval (14).

Non-resorbable membranes must be removed in a 2nd surgery, 4 to 6 weeks after their placement, and longer times provide no additional benefit $(10,56)$. Macedo et al. (57) evaluated, in dogs, the effect of early e-PTFE membrane removal (2 weeks after placement) in the periodontal regeneration of class II furcation defects. The results demonstrated that this procedure promoted the formation of new bone, cementum and periodontal ligament similar to the control group (membrane removal at 4 weeks after placement). The authors concluded that the early removal of the e-PTFE membranes, in dogs, does not influence the GTR results. Thus, the healing tissues formed under this membrane in two weeks seem to have physical and structural characteristics that inhibit the down-growth of epithelium and regenerate the periodontal tissues. Although, Machtei and Schallhorn (14) reported that membranes left in place for a period less than 4 weeks have a reduced prognosis, the effect of the early removal of the e-PTFE membranes in humans has not yet been demonstrated.

Regarding soft tissue coverage of the newly formed tissue following membrane retrieval, Bowers et al. (10) reported that furcations with incomplete coverage of the new tissue demonstrated a lower proportion of sites resolving with complete furcation closure than defects with complete tissue coverage.

Postoperative period and maintenance. Patients should maintain good oral hygiene, especially in the furcation area, because sites with minimal or no gingival inflammation have consistently better regenerative responses than sites with poor plaque control (16). Thus, a regular supportive periodontal treatment (SPT) program must be established to maintain low plaque and gingival indexes and consequently to ensure that the newly-regenerated tissues are maintained. Gottlow and Karring (58) compared newly-regenerated periodontal tissues versus normal healthy periodontium and suggested that the new tissues are stable when accompanied by a good SPT regimen. Newman (43) suggested that SPT for regenerated periodontal sites should be performed at least every 3 months during the first post-surgery year and then as needed to maintain health. Murphy and Gunsolley (44) concluded after a systematic review that a monthly frequency maintenance schedule results in probing depth reduction, but the use of this regimen does not statistically improve clinical attachment level outcomes in GTR.

\section{CONCLUSIONS}

It should be noted that there are many factors acting collectively that influence the final outcome of GTR in class II furcations. The clinician should consider aborting surgery if a multitude of minor negative factors are present in the same patient. Alternatively, if GTR is performed, a less favorable prognosis is to be anticipated. Wherever possible, adverse factors should be modified to improve the prognosis. For example, tobacco cessation and space-maintaining devices should be used in poorly space-maintaining defects. Implementation of these changes may result in better predictability and an improved regenerative response.

Further research standardizing the numerous factors that influence the regenerative status (patient selection, standardized defect, analysis of defect and furcation characteristics, large sample size, and standardized evaluation methods) would lead to better comparison of studies and would help to indicate the true impact of each factor on the final therapeutic result.

\section{RESUMO}

As lesões de bifurcação classe II constituem uma das principais indicações para a técnica de regeneração tecidual guiada. Entretanto, a regeneração periodontal deste tipo de defeito ósseo, embora possível, não é considerada um resultado totalmente previsível, principalmente em termos de completo preenchimento ósseo. Muitos fatores podem explicar a variabilidade nos resultados do tratamento regenerativo nas lesões de bifurcação classe II. O objetivo desta revisão de literatura foi avaliar o significado de fatores relacionados ao paciente (fumo, estresse, diabetes mellitus, AIDS e outras doenças agudas e debilitantes, e presença de bolsas periodontais em outros sítios da boca), às condições locais (anatomia da furca, morfologia do defeito, espessura gengival e mobilidade dentária), ao tratamento cirúrgico (controle de infecção, utilização de materiais para preenchimento ósseo, tipo de membrana e técnica cirúrgica) e ao período pós-operatório (controle de placa, exposição e remoção das membranas e terapia periodontal de suporte) para o sucesso da RTG no tratamento das lesões de bifurcação classe II.

\section{REFERENCES}

1. Caffesse RG, Nasjleti CE, Plotzke AE, Anderson GB, Morrison EC. Guided tissue regeneration and bone grafts in the treatment of furcation defects. J Periodontol 1993;64:1145-1153.

2. Luepke PG, Mellonig JT, Brunsvold MA. A clinical evaluation of a bioresorbable barrier with and without decalcified freeze-dried bone allograft in the treatment of molar furca- 
tions. J Clin Periodontol 1997;24:440-446.

3. De Leonardis D, Garg AK, Pedrazzoli V, Pecora GE. Clinical evaluation of the treatment of class II furcation involvements with bioabsorbable barriers alone or associated with demineralized freeze-dried bone allografts. J Periodontol 1999;70:8-12.

4. Eickholz P, Kim TS, Holle R. Regenerative periodontal surgery with non-resorbable and biodegradable barriers: results after 24 months. J Clin Periodontol 1998;25:666-676.

5. Caffesse RG, Nasjleti CE, Morrison EC, Sanchez R. Guided tissue regeneration: comparison of bioabsorbable and nonbioabsorbable membranes. Histologic and histometric study in dogs. J Periodontol 1994;65:583-591.

6. Caffesse RG, Mota LF, Quinõnes CR, Morrison EC. Clinical comparison of resorbable and non-resorbable barriers for guided tissue regeneration. J Clin Periodontol 1997;24:747752.

7. Simonpietri-C JJ, Novaes AB Jr, Batista EL Jr, Filho EJ. Guided tissue regeneration associated with bovine-derived anorganic bone in mandibular class II furcation defects. 6month results at re-entry. J Periodontol 2000;71:904-911.

8. Novaes AB Jr, Tamani JP, Oliveira PT, Palioto DB, Almeida AL. Root trunk concavities as a risk factor for regenerative procedures of class II furcation lesions in dogs. J Periodontol 2001;72:612-619.

9. Villaça JH, Rodrigues DC, Novaes AB Jr, Taba M Jr, Souza SL, Grisi MF. Root trunk concavities as a risk factor for regenerative procedures of class II furcation lesions in humans. J Periodontol 2004;75:1493-1499.

10. Bowers GM, Schallhorn RG, McClain PK, Morrison GM, Morgan R, Reynolds MA. Factors influencing the outcome of regenerative therapy in mandibular class II furcations: Part I. J Periodontol 2003;74:1255-1268.

11. Melcher AH. On the repair potential of the periodontal tissues. J Periodontol 1976;47:256-260.

12. Pontoriero R, Lindhe J. Guided tissue regeneration in the treatment of degree II furcations in maxillary molars. J Clin Periodontol 1995;22:756-763.

13. Novaes AB Jr, Novaes AB. Guided tissue regeneration versus hemisection in the treatment of furcation lesions. A clinical analysis. Braz Dent J 1992;3:99-102.

14. Machtei EE, Schallhorn RG. Successful regeneration of mandibular Class II furcation defects: An evidence-based treatment approach. Int $\mathrm{J}$ Periodontics Restorative Dent 1995;15:146-167.

15. Garrett S. Periodontal regeneration around natural teeth. Ann Periodontol 1996;1:621-666.

16. Machtei EE, Cho MI, Dunford R, Norderyd J, Zambon JJ, Genco RJ. Clinical, microbiological, and histological factors which influence the success of regenerative periodontal therapy. J Periodontol 1994;65:154-161.

17. Johnson GK, Hill M. Cigarette smoking and the periodontal patient. J Periodontol 2004;75:196-209.

18. Ah MKB, Johnson GK, Kaldhal WB, Pattl KD, Kalkwarf KL. The effect of smoking on the response to periodontal therapy. J Clin Periodontol 1994;21:91-97.

19. Tonetti MS, Pini-Prato G, Cortellini P. Effect of cigarette smoking on periodontal healing following GTR in infrabony defects. A preliminary retrospective study. J Clin Periodontol 1995;22:229-234.

20. Machtei EE, Oettinger-Barak O, Peled M. Guided tissue regeneration in smokers: Effect of aggressive anti-infective therapy in Class II furcation defects. J Periodontol
2003;74:579-584.

21. Kaldahl WB, Johnson GK, Patil KD, Kalkwarf KL. Levels of cigarette consumption and response to periodontal therapy. J Periodontol 1996;67:675-681.

22. Monteiro da Silva AM, Newman HN, Oakley DA. Psychosocial factors in inflammatory periodontal diseases. A review. J Clin Periodontol 1995;22:516-526.

23. Mattson JS, Gallagher SJ, Jabro MH, McLey LL. Complications associated with diabetes mellitus after guided tissue regeneration: case report. Compend Contin Educ Dent 1998;19:923-926.

24. Grossi SG, Skrepcinski FB, DeCaro T, Zambon JJ, Cummins D, Genco RJ. Response to periodontal therapy in diabetics and smokers. J Periodontol 1996;67:1094-1102.

25. Nowzari H, MacDonald ES, Flynn J, London RM, Morrison $\mathrm{JL}$, Slots J. The dynamics of microbial colonization of barrier membranes for guided tissue regeneration. J Periodontol 1996;67:694-702.

26. Horwitz J, Machtei EE, Reitmeir P, Holle R, Kim TS, Eickholz P. Radiographic parameters as prognostic indicators for healing of class II furcation defects. J Clin Periodontol 2004;31:105-111.

27. Mardam-Bey W, Majzoub Z, Kon S. Anatomic considerations in the etiology and management of maxillary and mandibular molars with furcation involvement. Int J Periodontics Restorative Dent 1991;11:398-409.

28. Trejo PM, Weltman RL. Favorable periodontal regenerative outcomes from teeth with presurgical mobility: A retrospective study. J Periodontol 2004;75:1532-1538.

29. Anderegg CR, Metzler DG, Nicoll BK. Gingiva thickness in guided tissue regeneration and associated recession at facial furcation defects. J Periodontol 1995;66:397-402.

30. Wikesjö UME, Nilvéus RE, Selvig KA. Significance of early healing events on periodontal repair: A review. J Periodontol 1992;63:158-165.

31. Pustiglione FE, Brazil CAB, Carvalho JCM, Kon S, Tristão GC. Root trunk dimension and concavity of the first lower molar. J Dent Res 1993;72(Special Issue):245(abstract 1136).

32. Kon S, Rios CM, Carvalho JCM, Pustiglione FE, Tristão GC. Tooth morphology: Dimension and concavity depth of the 2nd lower molar trunk. J Dent Res 1992;71(Special Issue):282(abstract 134).

33. Dunlap RM, Gher ME. Root surface measurement of the mandibular first molars. J Periodontol 1985;56:234-238.

34. Bower RC. Furcation morphology relative to periodontal treatment. Furcation entrance architecture. J Periodontol 1979;50:23-27.

35. Matia JI, Bissada NF, Maybury JE, Ricchetti P. Efficiency of scaling of the molar furcation area with and without surgical access. Int J Periodontics Restorative Dent 1986;6:24-35.

36. Hutchens LHJ. Hypothetical considerations in the regenerative treatment of molar furcation defects. Curr Opin Periodontol 1996;3:157-167.

37. Cortellini P, Pini-Prato G, Tonetti MS. Periodontal regeneration of human intrabony defects. II. Reentry procedures and bone measures. J Periodontol 1993;64:261-268.

38. Anderegg CR, Martin SJ, Gray JL, Mellonig JT, Gher ME. Clinical evaluation of the use of decalcified freeze-dried bone allograft with guided tissue regeneration in the treatment of molar furcation invasions. J Periodontol 1991;62:264-268.

39. Mormann W, Ciancio S. Blood supply of human gingiva following periodontal surgery (a fluoroscein angiographic study). J Periodontol 1977;48:681-692. 
40. Novaes AB, Ruben MP, Kon S, Goldman HM, Novaes AB Jr The development of the periodontal cleft. J Periodontol 1975;46:701-709.

41. Cortellini P, Tonetti MS, Lang NP, Suvan JE, Zucchelli G, Vangsted T, Silvestri M, Rossi R, McClain P, Fonzar A, Dubravec D, Adriaens P. The simplified papilla preservation flap in the regenerative treatment of deep intrabony defects: Clinical outcomes and post-operative morbidity. J Periodontol 2001;72:1702-1712.

42. Nowzari H, Matian F, Slots J. Periodontal pathogens on polytetrafluoroethylene membrane for guided tissue regeneration inhibit healing. J Clin Periodontol 1995;22:469-474

43. Newman MG. The role of infection and anti-infection treatment in regenerative therapy. J Periodontol 1993;64:11661170.

44. Murphy KG, Gunsolley JC. Guided tissue regeneration for the treatment of periodontal intrabony and furcation defects. A systematic review. Ann Periodontol 2003;8:266-302.

45. Black BS, Gher ME, Sandifer JB, Fucini SE, Richardson AC. Comparative study of collagen and expanded polytetrafluoroethylene membranes in the treatment of human class II furcation defects. J Periodontol 1994;65:598-604.

46. Bouchard P, Giovannoli JL, Mattout C, Davarpanah M, Etienne D. Clinical evaluation of a bioabsorbable regenerative material in mandibular class II furcation therapy. J Clin Periodontol 1997;24:511-518.

47. Eickholz P, Kim TS, Holle R, Hausmann E. Long-term results of guided tissue regeneration therapy with non-resorbable and bioabsorbable barriers. I. Class II furcations. J Periodontol 2001;72:35-42.

48. Sanz M, Zabalegui I, Villa A, Sicilia A. Guided tissue regeneration in human class II furcations and interproximal infrabony defects after using a bioabsorbable membrane barrier. Int J Periodont Res Dent 1997;17:563-573.
49. Yoshinari N, Tohya T, Mori A, Koide M, Kawase H, Takada T, Inagaki K, Noguchi T. Inflammatory cell population and bacterial contamination of membranes used for guided tissue regenerative procedures. J Periodontol 1998;69:460-469.

50. De Sanctis M, Zucchelli G, Clauser C. Bacterial colonization of barrier material and periodontal regeneration. J Clin Periodontol 1996;23:1039-1046.

51. Nowzari H, Slots J. Microorganisms in polytetrafluoroethylene barrier membranes for guided tissue regeneration. J Clin Periodontol 1994;21:203-210.

52. Bunyaratavej P, Wang HL. Collagen membranes: A review. J Periodontol 2001;72:215-229.

53. Pini Prato GP, Tinti C, Vincenzi G, Magnani C, Cortellini P, Clauser C. Guided tissue regeneration versus mucogingival surgery in the treatment of human buccal gingival recession. $\mathrm{J}$ Periodontol 1992;63:919-928.

54. Novaes AB Jr, Gutierrez FG, Francischetto IF, Novaes AB. Bacterial colonization of the external and internal sulci and of cellulose membranes at time of retrieval. J Periodontol 1995;66:864-869.

55. Cury PR, Sallum EA, Nociti FH Jr, Sallum AW, Jeffcoat MK. Long-term results of guided tissue regeneration therapy in the treatment of class II furcation defects: A randomized clinical trial. J Periodontol 2003;74:3-9.

56. Caffesse RG, Smith BA, Castelli WA, Nasjleti CE. New attachment achieved by guided tissue regeneration in beagle dogs. J Periodontol 1988;59:589-594.

57. Macedo GO, Souza SL, Novaes AB Jr, Grisi MF, Taba M Jr, Palioto DB. The effect of early membrane removal on the regeneration of class II furcation defects in dogs. J Periodontol 2005 (in press).

58. Gottlow J, Karring T. Maintenance of new attachment gained through guided tissue regeneration. J Periodontol 1992;19:315-317.

Accepted February 20, 2005 